- Basic Research

\title{
Effect of Oral Stimulation Technique Application on Promoting Feeding among Preterm Infants.
}

Hanaa Mohamed Ibrahim Nassar ${ }^{(1)}$ Asmaa Awad Helmy ${ }^{(2)}$, Manal Mohamed Ahmed Ayed ${ }^{(3)}$

(1) Pediatric Nursing Department, Faculty of Nursing, Port Said University, Egypt

(2) Pediatric Nursing Department, Faculty of Nursing, Helwan University, Egypt

(3) Pediatric Nursing Department, Faculty of Nursing, Sohag University, Egypt

\begin{abstract}
Introduction: Prematurity is associated with many difficulties in feeding due to inadequate coordination of sucking, swallowing, and breathing. Poor oralmotor developments among premature infants are common and required individualized therapy. Oral stimulation technique application may be effective in promoting oral feeding. Aim: To evaluate the effect of oral stimulation technique application on promoting feeding among preterm infants. Design: A quasi-experimental research design with a pretest-posttest was used. Sample: A purposive sample of 60 preterm infants within six months was divided into two groups: (a) study group (30 preterm infants), and (b) control group (30 preterm infants).
\end{abstract}

Setting: This study was conducted at the Neonatal Intensive Care Units (NICU) at Sohag University Hospital. Tools: Two tools were used: (I) Preterm infant medical record and (II) Preterm Infant Breastfeeding Behavior Scale (PBFBS).

Results: The results of the present study indicated that statistically significant differences were found between pre and post oral stimulation technique application for preterm infants regarding their feeding promotion. Conclusion: The current study concluded that oral stimulation technique application was effective in promoting feeding among preterm infants. Recommendations: It is very important to make further studies on oral stimulation technique effectiveness when caring for preterm infants as it is a safe and effective intervention in promoting oral feeding.

Keywords: Oral Stimulation Technique Application, Feeding, Preterm Infants, Nursing 


\section{Introduction:}

Preterm infants are the infants born before 37 weeks of gestational age. Prematurity considers the most common cause leading to mortality of infants due to their underdeveloped central nervous system and oral musculature. Preterm infants frequently experience oral feeding difficulties, with coordination lacking for the suck swallow-breath mechanism. Preterm infants rely on administered feedings and parenteral nutrition to ensure proper nutritional requirements are met. Adverse effects, however, are increased due to the lack of stimuli from the gastrointestinal tract (Glover \& Manuck, 2019).

Safe and successful suckle feeding, via breast or by the bottle, is one requirement for hospital discharge and an ultimate goal for preterm infant feeding. Thus, facilitating oral feeding skills and helping preterm infants transit to full oral feeding is a key focus for the medical staff of neonatal intensive care units (Lubbe, 2018).

Infants born before 37 weeks still experience problems at age of 12 months. Furthermore, improved preterm infant survival has increased the prevalence of feeding problems. Achievement of oral feeding is one of the most challenging milestones for preterm infants. Successful oral feeding while still in hospital leads to a rapid transition away from tube feedings; minimizes adverse events such as apnea, bradycardia, desaturation, and can reduce long-term consequences such as food aversion. Thus, any instrument or therapy that can improve oral skills not only ensures the safety and efficiency of oral feeding, but also shortens the length of hospitalization, improves the mother-infant relationship, and saves on hospital costs (Islami et al., 2017).

Many preterm infants have delayed establishment of oral (suck) feeding and are fed at first with feeding tubes or with intravenous (parenteral) nutrition. The development of oral feeding skills needs careful coordination of sucking, swallowing, and breathing. In preterm infants, the development of oral feeding can be challenging because of long hospitalizations, breathing difficulties, and other medical conditions associated with preterm infant (Glover \& Manuck, 2019).

Unpleasant procedures such as ventilation or frequent suctioning of secretions from the mouth or nose can impact negatively on feeding skills. International guidelines for the transition from tube feeding to oral feeding vary widely. Healthcare providers use a range of interventions to improve sucking and feeding skills in preterm infants, and studies report faster transition time from 
tube feeds to oral feeds, reduced length of hospitalization, and improve infants' sucking skills (Crowe et al., 2016).

Early oral motor interventions (OMIs) are beneficial for oral feeding in preterm infants. The OMI is defined as sensory stimulation of the lips, jaw, tongue, soft palate, pharynx, larynx, and respiratory muscles, which are thought to influence the physiological underpinnings of the oropharyngeal mechanism to improve its functions. Previous research abroad has shown that OMI can shorten the transition time from gavage feeding to full oral feeding and improve oral feeding efficiency (Glover \& Manuck, 2019).

Research showed that oral stimulation technique accelerates the transition from tube to oral feeding in preterm infants; the achievement of oral feeding has been viewed from new perspectives. Over the last 16 years, several studies have provided additional evidence of the benefits of this technique for early feeding (Rocha et al., 2017) reducing the transition period from tube to oral feeding, shortening the length of hospital stay (Da, 2020), and improving breastfeeding rates (Bache et al., 2014).

Inadequately trained nurses are the major risks for providing effective nursing care to preterm neonates. So nurses need continuous education and training to improve their performance. Education and training are potential means for implementing effective nursing care at (NICU), as they alter perception, increase knowledge, and in- turn change work practice. This education is provided by experienced nurses and other medical professionals who have qualified or experienced for educational tasks (Da, 2020). Nurses should be equipped with high levels of skilled nursing care, which included accurate assessment of feeding readiness and thoughtful progression to full oral feeding. Nurses can play an important role on enhancing oral feeding skills through oral sensory stimulation during preterm neonates' routine care (Mcgrath \& Braescu, 2004).

\section{Significance of the study:}

Although approximately half of the preterm deliveries are due to unknown causes and in general preterm infants, $71.3 \%$ are born during the late preterm period, it concluded that various risk factors lead to prematurity were; previous preterm birth, infection, multiple fetal pregnancies, inflammation, hypertension, diabetes, shortened cervix, and placenta previa. Prematurity is associated with feeding difficulties, preterm have lengthy hospital stays until preterm infants can had the ability to feed and sustain suck and swallow to improve growth and development (Pineda et al., 2020). 


\section{The study aim:}

To evaluate the effect of oral stimulation technique application on promoting feeding among preterm infants through:

- Assessing feeding ability of preterm infants.

- Assessing breastfeeding behavior of preterm infants.

- Evaluate the effect of oral stimulation technique application on promoting feeding among preterm infants according to their feeding ability and behavior.

\section{Research hypothesis:}

H1: The application of an oral stimulation technique will promote feeding ability and behavior among preterm infants.

$\mathrm{H} 2$ : Oral stimulation technique application will increase sucking strength and increase weight gain among preterm infants.

H3: Oral stimulation technique application will reduce the time needed to achieve exclusive oral feeding among preterm infants.

H4: Oral stimulation technique application will reduce time of hospitalization among preterm infants.

\section{Subjects and Methods:}

Design: A quasi-experimental research design was utilized in the current study to achieve the aim of the study. Setting: This study was conducted at the Neonatal Intensive Care Units at Sohag University Hospital; (consisted of two rooms, included ten incubators, the first room included five and the second room included five incubators). This setting was selected due to the high prevalence of preterm infants in the selected setting, and also it serves the biggest region of the population in rural and urban areas.

\section{Subjects:}

A purposive sample of 60 preterm infants was enrolled in the current study within six months and divided equally into two groups: (a) study group (30 preterm infants) and (b) control group (30 preterm infants), oral stimulation technique was given only to preterm infants in the study group. Control group received routine care of the NICU at Sohag University Hospital.

Sixty preterm infants were randomly assigned into the study group and the control group using computer-generated random number assignment. The 
sample was numbered from 1 to 60 using the random number generator feature in Microsoft Excel. Preterm infants that received odd numbers 1, 3, 5 were assigned to the study group while preterm infants receiving even numbers 2, 4, 6 were assigned to the control group, with the following criteria:

\section{Inclusion criteria included:}

- Preterm infants from 28-32 weeks of gestation.

- Preterm infants their weight 1500 grams or more.

- Male and female Preterm Infants with weak or absent sucking, swallowing, and breathing reflexes

\section{Inclusion criteria included:}

- Preterm infants suffering from congenital anomalies.

\section{Data collection tools:}

Tool I: Preterm infant medical record: for a preterm infant was developed by the researchers after reviewing the related literature and research studies (da, 2020, and Crowe, Chang, \& Wallace, 2016), it included two parts:

Part (1): It included data about preterm infants related to demographic data of preterm infants such as gender, gestational age, birth weight, and type of feeding.

Part (2): It included data about preterm infants feeding progress post oral stimulation technique application such as weight on discharge, length of hospital stay, days to transfer from tube to oral feeding, and amount of milk.

Tool (II): Preterm Infant Breastfeeding Behavior Scale (PBFBS): It was adapted from Nyqvist, Sjodén, \& Ewald, (1999) to assess preterm infants' breastfeeding behavior development.

The Premature Infant Breastfeeding Behavior Scale (PIBBS) was developed and validated to assess breastfeeding maturation among infants their age from 35 weeks gestation or less. It consisted of 6 items (a) rooting, (b) areola grasp, (c) latching and maintaining latch, (d) sucking, (e) longest sucking burst, and (f) swallowing.

\section{Scoring system:}

\section{Rooting: is scored zero to two}

No rooting.............................

Some rooting behavior...................1

Obvious rooting behavior.................2

Latch: is scored zero to three

None only touches the nipple............... 
Only part of the nipple.....................1

The whole nipple, but not the areola........2

Wide latch, all of the nipple and as much areola as possible...... 3

\section{Staying latched: is scored zero to three}

No latch at all.......................... .0

Latched on for $<5$ minutes.................. 1

Latched on for $6-10$ minutes.................2

Latched on for 11-15 minutes...............3

Sucking: is scored zero to four

No sucking at all...........................

Licking motion but no sucking................1

Short sucking bursts $(2-9$ sucks $) \ldots \ldots \ldots \ldots .2$

Repeated short sucking bursts and/or occasional long bursts (>10sucks)

..............3

Repeated $(>2)$ long sucking bursts $(>10$ sucks) .4

\section{Longest sucking bursts: is scored from one to six}

$1-5$ consecutive sucks.......................1

6-10 consecutive sucks....................2

11-15 consecutive sucks.....................3

16-20 consecutive sucks....................4

21-25 consecutive sucks....................5

$>26$ consecutive sucks....................6

\section{Swallowing: is scored zero to two}

No swallowing noticed..................... 0

Occasional swallowing..................... 1

Repeated swallowing..................... 2

\section{Validity of the tools:}

The validity of the tools was ascertained by a Jury of three experts' professors in the pediatric nursing field who reviewed the tools for content validity. They were asked also to judge the items for completeness and clarity. No modifications were done to the tools.

\section{Reliability of the tools}


Reliability was applied by the researchers to test the internal consistency of the tools. The Reliability of the first (Tool I) through Cronbach's alpha test $\alpha=$ 0.92 and 0.87 for the second tool.

\section{Methods:}

- Approval of the Ethical Research Committee of Sohag Faculty of Nursing was obtained before conducting the study.

- Official permission was obtained through an issued letter from the Dean of Faculty of Nursing, Sohag University, to conduct this study and the directors of the Neonatal Intensive Care Unit at Sohag University Hospital. The aim of the study was explained to obtain permission to collect the research data from the hospital.

- A pilot study was conducted on $10 \%$ of the preterm infants (6 preterm infants) to test clarity and testing of the feasibility of the research process, no modifications were carried out. So all preterm infants included in the study sample.

\section{The procedure of data collection:}

- Data were collected within six months from the beginning of March 2019 till the end of August 2019. Researchers attended the previously mentioned setting for data collection two days per week, from 9 am to 11 am.

- Implementation of the study included three phases (assessment phase, implementation phase, and evaluation phase).

\section{I- Assessment phase:}

The data collection tools were filled out by the researchers. The average time required for the completion of each tool was around 20-30 minutes. The tools used for collecting data were used for both a study and control groups (tool I, part 2, and tool II). Diagnosis, gestational age, birth weight, and date of birth of preterm infants were obtained from their medical records.

\section{Implementation Phase:}

\section{In the study group:}

- Thirty preterm infants were shared as a study group who received oral stimulation technique applications.

- Before starting the oral stimulation technique application the researchers were placing the preterm infant in the prone position and waking up them.

- The study group received the oral stimulation technique application. 
- The oral stimulation technique consisted of a 15-minute stimulation technique, whereby the first 12 minutes involved stroking the cheeks, lips, gums, and tongue, and the final 3 minutes consisted of sucking on a pacifier routinely used in the nursery.

- The technique was administered once per day for seven consecutive days, 15 to 30 minutes

In the control group:

- Thirty preterm infants were shared as a control group who did not receive oral stimulation technique and received routine care only of the study setting.

\section{Evaluation phase:}

In both the study and control groups, the researchers reassess preterm infants feeding progress following oral stimulation application (weight on discharge at the end of the oral stimulation technique application, length of hospital stay, days to transfer from tube to oral feeding, frequency of feeding, and amount of milk) after oral stimulation technique application after two weeks of the application using the same tools in both groups (tools I, part 2 and II as posttest).

\section{Ethical considerations:}

During dealing with and executing oral stimulation technique for preterm infants, all ethical issues were ensured. The researchers informed parents that, the study was voluntary, they were allowed to refuse to participate, and they had the right to withdraw from the study at any time, without giving any reason. Moreover, they were assured that their information would be confidential and used for research purposes only.

\section{Statistical analysis:}

Data were collected and entered the computer using SPSS 18 (statistical package for the social science) (SPSS Inc., Chicago, Illinois, USA), a program for statistical analysis version 22. Data were entered as numerical or categorical, as appropriate. Two types of statistics were done: (a) descriptive statistics, in which quantitative data were expressed in means $\pm \mathrm{SD}$, and (b) qualitative data, which were expressed in number (frequency) and percent (\%). Analytical statistics were done by using Paired t-test and Fisher exact test to measure the association between qualitative variables as appropriate. 
Moreover, the Student t-test, which is a test of significance, was used for comparison between two groups having quantitative variables. Mann-Whitney test (nonparametric test), which is a test of significance, was used for comparison between two groups not normally distributed having quantitative variables. The level of significance used was $95 \%$, so the P-value of more than 0.05 was considered statistically non-significant, the P-value of less than 0.05 was considered statistically significant, and the P-value of less than 0.001 was considered statistically highly significant.

\section{Results:}

Table (1) showed that (56\% and 59\%) of the study and control groups were males respectively. The mean \pm gestational age of preterm infants was $30.4 \pm 1.5$ weeks in the study group and $30.7 \pm 1.2$ in control group. Regarding birth weight, $77 \%$ and $75 \%$ of preterm infants in the study and control groups were $\geq$ 2.000 grams. In addition, the same table illustrated the type of feeding among the studied preterm infants before oral stimulation implementation, it was noticed that no one of them was breastfed, while the majority of them $(93 \%$ and $96 \%)$ in the study and control groups were fed by nasogastric tube respectively. No statistically significant differences between study and control groups regarding their demographic data $(\mathrm{P}>0.05)$.

Table (2) represented the difference of PIBBS items regarding breastfeeding behaviors. It was observed that, no significant difference was found regarding rooting effort $(\mathrm{M}=0.68, \mathrm{SD}=-0.31, \mathrm{p}=0.192)$, latch effort $(\mathrm{M}=$ $0.22, \mathrm{SD}=0.43, \mathrm{p}=0.169)$, or observed swallowing $(\mathrm{M}=0.70, \mathrm{SD}=-0.52, \mathrm{p}=$ $0.053)$. While, a significant difference in scores was detected for staying latched $(\mathrm{M}=-1.0, \mathrm{SD}=.83, \mathrm{p}=0.004)$, sucking effort $(\mathrm{M}=-0.92, \mathrm{SD}=0.76, \mathrm{p}=0.003)$, and longest sucking burst $(\mathrm{M}=-1.41, \mathrm{SD}=1.08, \mathrm{p}=0.003)$ respectively which mean an improvement was occurred regarding these items of breastfeeding among preterm infants after oral stimulation technique application from NICU admission till discharge.

Table (3) illustrated feeding progress and outcomes among preterm infants in both groups after oral stimulation technique application and revealed that weight on discharge among the studied preterm infants after oral stimulation technique implementation was increased and $77 \%$ and $60 \%$ of them their weight on discharge was from $2.000-<2.500$ kilograms and was higher among the study group compared with the control group $(\mathrm{P}<0.001)$ respectively. It was observed that $62 \%$ of preterm infants were breastfed after oral stimulation technique application in the study group compared to no one was breastfed in the control 
group, while $29 \%$ were bottle feeding and $9 \%$ of them were nasogastric tube feeding. Concerning the amount of milk intake among the preterm infants, it was found that amount of milk intake among preterm infants in the study group increased to $90 / \mathrm{ml}$ each time after oral stimulation technique implementation compared to $10 \mathrm{ml} /$ in each time fed by control group.

In addition, the length of hospital stay was significantly shorter $8.9 \pm 2.3$ among the study group compared with the control group was $11.8 \pm 3.7(\mathrm{P}<0.001)$; the period of parenteral feeding was significantly shorter in study group $3.9 \pm 1.8$ when compared with the control group was $5.2 \pm 1.6(\mathrm{P}=$ 0.004 ), and there were significant differences in the mean oral feeding duration between two groups, as it was reduced in the study when compared with the control group $(\mathrm{P}=0.04)$. The transition time was reduced significantly in the study group $(\mathrm{P}<0.001)$ after oral stimulation technique implementation. There were statistically significant differences between preterm infants in study and control groups regarding all items of feeding progress after oral stimulation technique implementation. 
Table (1): Distribution of the studied preterm infant in both groups regarding their demographic characteristics $(n=60)$

\begin{tabular}{|c|c|c|c|c|c|c|}
\hline \multirow[t]{2}{*}{ Items } & \multicolumn{2}{|c|}{$\begin{array}{c}\text { Study group } \\
\text { (30) } \\
\end{array}$} & \multicolumn{2}{|c|}{$\begin{array}{c}\text { Control group } \\
((\mathbf{3 0} \\
\end{array}$} & \multirow[t]{2}{*}{ t-test } & \multirow{2}{*}{$\begin{array}{l}P \text { - } \\
\text { value }\end{array}$} \\
\hline & .No & $\%$ & .No & $\%$ & & \\
\hline \multicolumn{7}{|l|}{ :Gender } \\
\hline - Male & 17 & 56 & 18 & 59 & \multirow[t]{2}{*}{0.34} & \multirow[t]{2}{*}{0.57} \\
\hline - Female & 13 & 44 & 12 & 41 & & \\
\hline $\begin{array}{l}\text { Gestational age in } \\
\text { weeks }\end{array}$ & \multicolumn{2}{|c|}{$30.4 \pm 1.5$} & \multicolumn{2}{|c|}{$30.7 \pm 1.2$} & & \\
\hline $28 \leq 30$ & 10 & 33 & 11 & 36 & \multirow{3}{*}{1.06} & \multirow{3}{*}{0.28} \\
\hline $30 \leq 32$ & 20 & 67 & 19 & 64 & & \\
\hline Mean \pm SD & & 1.5 & & & & \\
\hline \multicolumn{7}{|l|}{ Birth weight } \\
\hline$-\quad 1.500-\leq 2.000$ & 7 & 23 & 8 & 25 & \multirow{3}{*}{0.35} & \multirow{3}{*}{0.72} \\
\hline$-\quad \geq 2.000$ & 23 & 77 & 22 & 75 & & \\
\hline Mean \pm SD & & 147 & \pm 552 & & & \\
\hline \multicolumn{7}{|l|}{ Type of feeding } \\
\hline - $\quad$ Bottle feeding & 2 & 7 & 1 & 4 & \multirow[t]{2}{*}{0.33} & \multirow[t]{2}{*}{0.45} \\
\hline - $\quad$ NGT feeding & 28 & 93 & 29 & 96 & & \\
\hline
\end{tabular}

Table (2): Difference in Preterm Infant Breastfeeding Behavior Scale scores $(\mathbf{n}=60)$

\begin{tabular}{||l|c|c|c|c|c|c|c||}
\hline \multirow{2}{*}{\multicolumn{1}{|c|}{ Items }} & \multicolumn{6}{|c|}{ Last 95\% CI of the differences between PIBBS } \\
\cline { 2 - 8 } & Mean & SD & Lower & Upper & T & df & $\mathbf{p}$ \\
\hline Rooting effort & .68 & .31 & -.77 & .17 & -1.42 & 9 & .192 \\
\hline Latch effort & -0.22 & .43 & .12 & .12 & -1.52 & 9 & .169 \\
\hline Staying latched & 1.0 & .83 & .25 & -.43 & -3.86 & 9 & .004 \\
\hline Sucking effort & .92 & .76 & .24 & -.38 & -3.76 & 9 & .004 \\
\hline Longest sucking burst & -1.41 & 1.08 & .35 & -.62 & -4.13 & 9 & .003 \\
\hline Swallowing & .70 & .52 & .23 & .02 & -2.23 & 9 & .053 \\
\hline
\end{tabular}


Table (3): Comparison of feeding progress and outcomes among preterm infants in both groups after oral stimulation technique application $(n=60)$

\begin{tabular}{|c|c|c|c|c|c|c|}
\hline \multirow[t]{2}{*}{ Items } & \multicolumn{2}{|c|}{ Study group (30) } & \multicolumn{2}{|c|}{$\begin{array}{c}\text { Control } \\
\text { group (30) }\end{array}$} & \multirow[t]{2}{*}{$\mathbf{X} 2$} & \multirow[t]{2}{*}{ P-value } \\
\hline & .No & $\%$ & .No & $\%$ & & \\
\hline \multicolumn{7}{|l|}{ Weight on discharge } \\
\hline $\begin{array}{lll}- & 1.500-\leq \\
2.000 & & \\
\end{array}$ & 5 & 17 & 11 & 36.6 & \multirow{3}{*}{10.3} & \multirow{3}{*}{$<0.001 * *$} \\
\hline $\begin{array}{rrrr}- & 2.000 \\
2.500 & & < \\
\end{array}$ & 23 & 77 & 18 & 60 & & \\
\hline $\begin{array}{lll}- & 2.500 & \text { and } \\
& \text { more }\end{array}$ & 2 & 6 & 1 & 3.4 & & \\
\hline \multicolumn{7}{|c|}{ Transfer from tube to oral feeding } \\
\hline - $\quad$ Breastfeeding & 18 & 62 & 0 & 0 & \multirow{3}{*}{13.7} & \multirow{3}{*}{$<0.05$} \\
\hline$-\quad$ Bottle feeding & 9 & 29 & 2 & 7 & & \\
\hline - $\quad$ NGT feeding & 3 & 9 & 28 & 93 & & \\
\hline $\begin{array}{|lll|}\begin{array}{l}\text { Amount } \\
\text { intake }\end{array} & \text { of milk } \\
\end{array}$ & \multicolumn{2}{|c|}{$90 \mathrm{~mL} /$ each time) } & \multicolumn{2}{|c|}{$\begin{array}{l}10 \mathrm{~mL} / \mathrm{each} \\
\text { time }\end{array}$} & 14.9 & $<0.05$ \\
\hline $\begin{array}{l}\text { length of hospital } \\
\text { stay pre/post oral } \\
\text { stimulation } \\
\text { technique } \\
\text { application } \\
\end{array}$ & \multicolumn{2}{|c|}{$8.9 \pm 2.3$} & \multicolumn{2}{|c|}{$11.8 \pm 3.7$} & 3.5 & $<0.001 * *$ \\
\hline $\begin{array}{l}\text { Period of parenteral } \\
\text { feeding (days) }\end{array}$ & \multicolumn{2}{|c|}{$3.9 \pm 1.8$} & \multicolumn{2}{|c|}{$5.2 \pm 1.6$} & 3.0 & $<0.004 * *$ \\
\hline $\begin{array}{|lc|}\text { Oral feeding } \\
\text { duration (days) }\end{array}$ & \multicolumn{2}{|c|}{$20.2 \pm 0.3$} & \multicolumn{2}{|c|}{$21.5 \pm 0.8$} & 2.04 & $<0.04 *$ \\
\hline $\begin{array}{l}\text { Transition time from } \\
\text { beginning oral } \\
\text { feeding till full oral } \\
\text { feeding }\end{array}$ & \multicolumn{2}{|c|}{$4.6 \pm 1.2$} & \multicolumn{2}{|c|}{$6.2 \pm 1.2$} & 4.2 & $<0.001 * *$ \\
\hline
\end{tabular}

$\mathrm{P}>0.05$ mean statistically no significant, ${ }^{*} \mathrm{P}<0.05$ statistically significant, $* * \mathrm{P}<0.001$ statistically highly significant. 


\section{Discussion:}

Problems related to oral feeding among preterm infants often lead to delayed hospital discharge, maternal stress, and associated long-term health problems. Preterm infants are not able to start oral feeding on the bottle or breastfeed immediately after birth due to weak muscle tone, oral-motor control immaturity, and poor suck and swallow reflexes (Lawrence \& Lawrence, 2017).

Also, the transition from tube feeding to oral feeding considered a challenge for preterm infants, because it requires coordination ability of the jaw muscles, lips, tongue, palate and pharynx, upper trunk, and respiratory systems to maintain a safe suck and swallow. Early oral-motor control immaturity can shorten the transition time from tube feeding to full oral feeding (Han et al., 2020).

Concerning preterm infant's gender, the present study revealed that in the two both groups, more than half of the studied preterm infants were males. The result is not similar with the result of Amer (2015) who studied the effect of prefeeding oral stimulation program on preterm infant feeding performance and found that more than half of the studied preterm infant's in the study group were females.

The results illustrated that found that the highest mean age among the preterm infants was in control group. This finding similar with Amer (2015) who conducted a study to assess the effect of prefeeding oral stimulation program on preterm infant feeding performance and found that the highest mean age was detected among preterm neonates in the same group.

Results of the present study indicated that, a significant difference and improvement in scores was detected for staying latched, sucking effort, and longest sucking burst. From the researchers' point of view, this reflects improvement of the preterm ability to receive oral feeding after oral stimulation technique and also, indicated the importance and positive effects of implementing the oral stimulation technique.

Results of the present study indicated an improvement and increased in weight on discharge among studied preterm infants after oral stimulation technique implementation. Similar findings were observed by Bache et al., (2014) who found in their study titled with "Effects of Oral Stimulation on Oral Feeding among Preterm Infants" that on discharge, they found that the percentage of weight change on discharge and was significantly higher among the 
intervention group $(11.93 \pm 3.86)$ compared with the control group $(9.2 \pm 5.2)$, with a P-value of 0.040 .

Results of the present study revealed that about two-thirds of them were breastfed after oral stimulation technique application. From the researchers' point of view, the result indicates the positive effects of oral stimulation technique application. This finding go with Sasmal et al., (2020) in the study titled "Effect of Prefeeding Oromotor Stimulation (OMS) on preterm Infants: A Systematic Review" that feeding mode at discharge is assessed and have reported that the OMS group achieve higher breastfeeding.

The present study indicated that amount of milk intake increased to 90/ $\mathrm{ml}$ each time after oral stimulation technique implementation. From the researchers' point of view, this result indicates the positive effect and importance of receiving oral stimulation for preterm infants in improving their sucking and swallowing that associated with increasing of amount of milk intake. This result could be explained by the fact that intra-oral stimulation applied to the study group's upper and lower gums improved tongue range of motion, supported suck to strengthen suction, and stimulated swallowing to increase milk intake per suck. This result agrees with Amer (2015), who studied the effect of prefeeding oral stimulation program on feeding performance of preterm infants and found that preterm neonates in the intervention group had the highest mean milk intake, while preterm neonates in the control group had the lowest mean milk intake.

Similar, Hwang (2018) conducted a study on the effects of prefeeding oral stimulation on preterm feeding performance, and discovered that a 5-minute prefeeding oral stimulation on feeding performance of preterm feeding and who found that a 5- minute prefeeding oral stimulation had significantly increased total oral intake rate in the study group at the end of the study. The finding supported by Lau et al., (2016) who conducted a study on the impact of nonnutritive oral motor stimulation and infant massage therapy on preterm infants' oral feeding skills and found that nonnutritive oral motor stimulation combined with infant massage therapy accelerated the maturation of infants' oral feeding skills, as evidenced by increased formula intake within the first five minutes of starting the feeding.

Also, this finding agrees with the study done by Da, (2020) the titled "Impact of A Pre-Feeding Oral Stimulation Program on First Feed Attempt in Preterm Infants: Double-Blind Controlled Clinical Trial" who illustrates the mean difference of the percentage of volume of breast milk taken via oral route 
in the first 8 days after initial assessment the Infants in GII were less likely to achieve $100 \%$ oral feeding than those in GI, over the same period $(\mathrm{p}=0.024)$

Results of the present study indicated that the length of hospital stay was less and short among the study group compared with the control group. These findings are supported by Lessen, (2016) conducted a study to evaluate the effect of the premature infant oral motor intervention on feeding progression and length of stay in preterm infants and reported that difficulties in oral feeding led to longer hospital stays with higher costs and found that the hospital stay was significantly shorter among intervention group when compared with the control group ( $\mathrm{P}$ 0.05). Similarly, El Mashada et al., (2021) revealed that days of hospital stay were significantly shorter among the intervention group when compared with the control group $(\mathrm{P}<0.05)$.

Results of the present study revealed that the period of parenteral feeding was significantly shorter in study group $3.9 \pm 1.8$ when compared with the control group was 5.2 \pm 1.6 . This result agrees with Peng, (2018), who studied oral feeding readiness among hospitalized preterm infants and found that the mean score period of parental feeding was significantly shorter in the intervention group (2.7 \pm 1.7$)$ compared with the control group (4.1 \pm 1.42$)$. Similarly, Greene et al., (2016) found that the mean score period of parental feeding in the intervention group was $3.7 \pm 1.7$ and in the control, group was $25.38 \pm 13.675$; with statistically significant difference between both groups. Results of the present study indicated that there were significant differences with reducing in the mean score of oral feeding duration in the study group when compared with the control group $(\mathrm{P}=0.04)$.

The study group's oral feeding time was reduced because prefeeding oral stimulation aided the upward movement of the jaw, reducing the effort required by the newborn to suck from a bottle and, as a result, the oral feeding duration was reduced. This finding is in line with that of Hwang et al. (2018), who investigated the effects of prefeeding oral stimulation on preterm feeding performance and discovered that a 5-minute prefeeding oral stimulation significantly reduced oral feeding duration in the intervention group compared to the control group.

The results are like a study conducted by McFarland et al., (2017) titled with "Oral and Non-Oral Sensorimotor Interventions Promote Oral Feeding Activity in Preterm Infants" and observed that the mean score of oral feeding duration has a statistically significantly lower difference in the intervention group $(34.70 \pm 1.03)$ when compared with the control group (35.66 \pm 1.49$)$. 
Results of the current study revealed that after receiving oral stimulation technique, the transition time to full oral feeding was reduced significantly in the intervention group $(\mathrm{P}<0.001)$. The result is in the line with Karagol et al., (2017) conducted a study titled with "Randomized Controlled Trial of Slow Versus Rapid Enteral Feeding Advancements on The Clinical Outcomes of Preterm Infants with Birth Weight" who found that the time from first successful oral feeding until full oral feeding was significantly lower in the experimental group, with a mean score of transition time was $3.7 \pm 3.5$ days, when compared to control group $(9.3 \pm 7.7$ days $)(\mathrm{P}<0.05)$.

Results of the present study matched with the study hypotheses and aim which reflected the success of the Implementation of the oral stimulation technique and improve sucking of preterm infants, in addition, it helps shorten the transition time of the preterm infants from tube feeding to complete oral feeding.

\section{Conclusions:}

Based on the findings and hypotheses of the current study, it was concluded that oral stimulation technique application has increased sucking strength and improved weight gain among preterm infants. Oral stimulation technique shortens preterm infants' hospital stay, reduce time needed and days to start and achieve exclusive oral feeding and shorten the duration of parenteral nutrition. Oral stimulation technique application was effective in promoting feeding ability among preterm infants.

\section{Recommendations:}

- It is very important to make further studies on oral stimulation technique effectiveness when caring for preterm infants as it is a safe and effective intervention in promoting oral feeding.

- The training program should be provided for all nurses working in NICUs as regards applying oral stimulation technique and should incorporate in their care with preterm infants.

- A training program should be provided for all mothers of preterm infants to encourage them to provide oral stimulation technique for their preterm infants.

- Simplified booklets about oral stimulation technique should be provided to mothers of preterm infants 
- Further study should be applied in all NICUs to assess and evaluate the nurse's knowledge, attitudes, and performance regarding oral stimulation technique and its effect on the health status of preterm infants.

- Future research includes replication of the current study on a large group.

\section{References:}

1. Amer H. Effect of prefeeding oral stimulation program on feeding performance of pretrerm infants, Pediatric department, Faculty of nursing, Cairo University, Journal of Biology, Agriculture and Healthcare; 2015, 28(4).

2. Bache M, Pizon E, Jacobs, J, Vaillant M, \& Lecomte A. Effects of pre-feeding oral stimulation on oral feeding in preterm infants: a randomized clinical trial. Early Human Dev. 2014; p.125-129.

3. Crowe L, Chang A, Wallace K. Instruments for assessing readiness to commence suck feeds in preterm infants: effects on time to establish full oral feeding and duration of hospitalization. Cochrane Database Syst Rev ;( 8): CD005586. 2016; Epub /08/24. https://doi.org/10.1002/14651858.CD005586.pub3 PMID: 27552522; PubMed Central PMCID: PMC6464358.

4. Da R. Impact of a pre-feeding oral stimulation program on first feed attempt in preterm infants: Double-blind controlled clinical trial'. 2020; PLOS ONE, 15(9 September). Doi: 10.1371/journal.pone.0237915.

5. El Mashada M, El Saieda M, Mekawy A. Effect of an early oral stimulation program on oral feeding in preterm neonates, Menoufia Medical Journal. 2021; p. 226-230.

6. Fucile S, Gisel E, Lau C. Oral stimulation accelerates the transition from tube to oral feeding in preterm infants. J Pediatr. 2002; 141(2):230e6.

7. Glover AV, Manuck TA. Screening for spontaneous preterm birth and resultant therapies to reduce neonatal morbidity and mortality, Semin Fetal Neonatal Med. 2019; 23(2): $1-2$

8. Greene Z, Donnell CP, Walshe M. Oral stimulation for promoting oral feeding in preterm infants. Cochrane Database Syst Rev. 2016; 9:25-31.

9. Han C, Shin J, Jeon GW. Development of Swallowing Function in Infants with Oral Feeding Difficulties', International Journal of Pediatrics. 2020; p. 1-7. Doi: $10.1155 / 2020 / 5437376$.

10. Hwang S. Effects of prefeeding oral stimulation on feeding performance of preterm feeding. "A thesis Submitted in partial fulfillment of the requirements for the degree of Doctor of Science" Boston University Sargent college of health and rehabilitation sciences; 2018.

11. Islami Z, Fallah R, Mosavian T. Growth parameters of NICU admitted low birth weight, preterm neonates, at corrected ages of 6 and 12 months. Iran J Reprod Med. 2017; 10: 459-464. 25246912.

12. Karagol BS, Zenciroglu A, Okumus N, Polin RA. Randomized controlled trial of slow vs rapid enteral feeding advancements on the clinical outcomes of preterm infants with birth weight 750-1250 g. J Parenter Enteral Nutr. 2017; p.223-228. 
13. Lau C., Fucile S, Gisel E. Impact of nonnutritive oral motor stimulation and infant massage therapy on oral feeding skills of preterm infants, Journal of neonatal-prenatal medicine; 2016, 5(4): 311-315.

14. Lawrence RA, Lawrence RM. Breastfeeding: a guide for the medical profession. Health Sci. 2017; p.33-38.

15. Lessen BS. Effect of the premature infant oral motor intervention on feeding progression and length of stay in preterm infants. Adv Neonatal Care. 2016; 11:129-139.

16. Lubbe W. Clinicians guide for cue-based transition to oral feeding in preterm infants: An easy-to-use clinical guide. J Eval Clin Pract. 2018; 24(1):80-8. Epub /03/03. https://doi.org/10.1111/jep.12721 PMID: 28251754; PubMed Central PMCID: PMC5901413.

17. Maciejewski M. Quasi-Experimental design. Biostatistics \& Epidemiology, 2020; 4 (1): 38-47.

18. McFarland DH, Fucile S, Gisel EG, Lau C. Oral and non-oral sensorimotor interventions enhance oral feeding performance in preterm infants. Dev Med Child Neurol. 2017; p.829-835.

19. McGrath J, and Braescu A. State of the science: feeding readiness in the preterm infant. J Perinat Neonatal Nurs; 2014, 18(4): pp. 353-368.

20. Nyqvist KH, Sjodén P, Ewald U. The development of preterm infants' breastfeeding behavior. Early Human Development. VERY OLD 1999; p.247264.

21. Peng WT. A study on oral feeding readiness in hospitalized preterm infants. Beijing: Beijing Union Medical College School of Nursing. 2018; p. 11-73. Pineda $\underline{\mathrm{R}}$, Danielle P, Jenny R, Molly G, Joan S. Preterm infant feeding performance at term equivalent age differs from that of full-term infants', journal of perinatology. 2020; 40(17 February), pp. 646-654. Doi: 10.1038/s41372-020-0616-2.

22. Rocha AD, Moreira ME, Pimenta HP, Ramos JR, Lucena SL. A randomized study of the efficacy of sensory-motor-oral stimulation and non-nutritive sucking in very low birth weight infant. Early Hum Dev. 2017; 83(6):385-8.

23. Sasmal S, Shetty A, Saha, B. Effect of Prefeeding Oromotor Stimulation on Preterm Infants: A Systematic Review. International Journal of Health Sciences and Research Vol.10; Issue: 12; December 2020 Website: www.ijhsr.org. ISSN: 2249-9571 


\section{الملخص العربي}

\section{تأثير تطبيق تقنية التحفيزعن طريق الفم في تعزيز التغذية بين الاطفال المبتسرين}

المقدمة: ترتبط فترة الخداج بالعديد من الصعوبات في الرضاعة بسبب عدم كفاية التنسيق بين المص

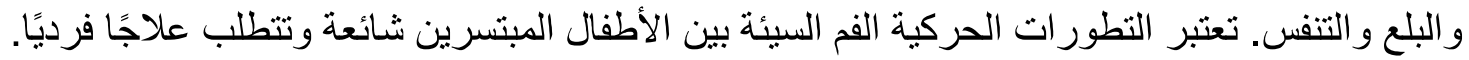

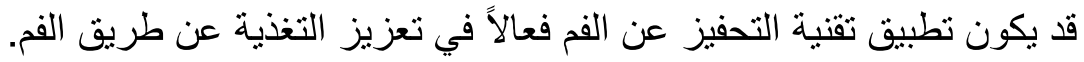

الهدف من الاراسة: تقييم تأثثر تطبيث تقنية التحفيز عن الفم على تعزيز التغذية بين الأطفال المبتسرين.

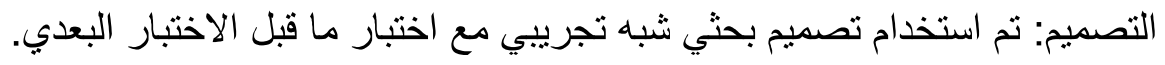

العينة: تم تقسيم عينة محتمله من 60 خديجًا خلال ستة أشهر إلى مجمو عتين: (أ) مجموعة الدر اسة (30 (30) طفل مبتسر) و (ب) مجمو عة المر اقبة (30 طفل مبن مبنس فئسر).

مكان جمع العينة: أجريت هذه الدراسة في وحدات العناية المركزة لحديثي الو لادة (NICU) بمستشفى الأدي جامعة سوهاج. الأدوات: تم استخدام أداتين: (I) السجل الطبى للاطفال المبتسرين و (II) مقياس سلوك الرضاعة الطبيعية للرضع قبل الأوان (PBFBS).

النتائج: أشارت نتائج الدراسة الحالية إلى وجود فروق ذات دلالة إحصائية بين تطبيق ثقنية التحفيز عن طريق الفم قبل وبعد تطبيق أسلوب التحفيز عن الاطفال المبتسرين فيما يتعلق بتعزيز تغذيتهم. الخلاصة: خلصت الدر اسة الحالية إلى أن تطبيق تقنية التحفيز عن طريق الفم فعال في تعزيز التغذية بين الاطفال المبتسرين.

التوصيات:_من المهم جدًا إجر اء مزيد من الدر اسات حول فعالية تقنية التحفيز عن طريث الفم عند رعاية الاطفال المبتسرين كتدخل آمن وفعال في تعزيز التغذية عن طريق الفم. . الكلمات المفتاحية: تطبيق تقنية التحفيز عن طريق الفم ، التغذية ، الاطفال المبتسرين. 